\title{
Childhood family income, adolescent violent criminality and substance misuse: quasi-experimental total population study
}

\author{
Amir Sariaslan, Henrik Larsson, Brian D'Onofrio, Niklas Långström and Paul Lichtenstein
}

\section{Background}

Low socioeconomic status in childhood is a well-known predictor of subsequent criminal and substance misuse behaviours but the causal mechanisms are questioned.

\section{Aims}

To investigate whether childhood family income predicts subsequent violent criminality and substance misuse and whether the associations are in turn explained by unobserved familial risk factors.

\section{Method}

Nationwide Swedish quasi-experimental, family-based study following cohorts born 1989-1993 $\left(n_{\text {total }}=526167\right.$, $\left.n_{\text {cousins }}=262267, n_{\text {siblings }}=216424\right)$ between the ages of 15 and 21 years.

\section{Results}

Children of parents in the lowest income quintile experienced a seven-fold increased hazard rate (HR) of being convicted of violent criminality compared with peers in the highest quintile ( $\mathrm{HR}=6.78,95 \% \mathrm{Cl} 6.23-7.38)$. This association was entirely accounted for by unobserved familial risk factors $(\mathrm{HR}=0.95,95 \% \mathrm{Cl} 0.44-2.03)$. Similar pattern of effects was found for substance misuse.

\section{Conclusions}

There were no associations between childhood family income and subsequent violent criminality and substance misuse once we had adjusted for unobserved familial risk factors.

\section{Declaration of interest} None.
Poverty or low socioeconomic status (SES) during childhood is a well-known distal risk factor for subsequent criminal and substance misuse behaviours. ${ }^{1,2}$ Recently, a Norwegian total population study found that children of parents in the lowest income decile were twice as likely to be convicted of a violent or drug crime compared with their peers in the fifth decile. ${ }^{3}$ Similarly, a number of longitudinal USA studies have linked low income levels with substance use disorders. ${ }^{4,5}$ Nevertheless, these findings could potentially result from inadequate adjustment of familial risk factors. ${ }^{6}$ Behavioural genetic investigations have found that the liabilities for both violent offending and substance misuse are substantially influenced by shared genetic and, to a lesser extent, family environmental factors. ${ }^{7,8}$ Consequently, it has been proposed that quasi-experimental, genetically informative research designs that explicitly take such factors into account could be integral in elucidating the causal mechanisms further. ${ }^{9}$ A few smaller quasi-experimental studies have been performed to date and they suggest that the inverse associations between parental income during childhood and development of behavioura problems remain after such adjustments. ${ }^{10-13}$ The generalisability of these findings is still questioned because of potential selection bias. Determining the causal nature of these associations is crucial to inform policy and clinical preventive efforts.

\section{Method}

\section{Sample}

We linked data from nine Swedish, longitudinal, total-population registers maintained by governmental agencies. The linkage was possible through the unique 10-digit civic registration number assigned to all Swedish citizens at birth and to immigrants upon arrival to the country. We were granted access to de-identified linked data after approval from the Regional Research Ethics Committee at Karolinska Institutet.
The following nine registers were used: (a) the Total Population Register (TPR) contained basic information (for example, gender and date of birth) for all individuals registered as inhabitants of Sweden; (b) the Multi-Generation Register supplied data that linked index individuals found in the TPR to their biological parents, thus enabling us to connect siblings; (c) the Medical Birth Register included pregnancy data with close to full coverage $(>99 \%)$ of all births in Sweden since $1973 ;{ }^{14}$ (d) the Education Register contained information on highest level of completed formal education; (e) the Cause of Death Register provided data on principal and contributing causes of death since 1958; (f) the Migration Register supplied data on dates for migration into or out of Sweden; ( $g$ ) the Integrated Database for Labour Market Research (LISA) provided annual information on family disposable income and welfare recipiency since 1990 on all individuals 16 years of age and older who were registered in Sweden as of December 31 for each year; (h) the National Patient Register provided data on psychiatric in-patient care since 1973 (ICD-8, -9 and -10) $)^{15-17}$ and out-patient care since 2001 (ICD-10); and (i) the National Crime Register supplied detailed information on all criminal convictions in lower general court in Sweden since 1973. Plea bargaining is not allowed and conviction data include all individuals who received custodial or non-custodial sentences; also those cases where the prosecutor decided to caution or fine. Only individuals age 15 or older are legally responsible in Sweden; hence, we were not able to study criminal offending prior to age 15 .

A total of 594127 children were born in Sweden between 1989 and 1993 and registered in the Medical Birth Registry. We chose to exclude children from multiple births $(n=14670)$, those who had serious malformations at birth $(n=20905)$ or who could not be linked to their biological parents $(n=3956)$. Furthermore, we excluded data for children who had either died $(n=2525)$ or emigrated from Sweden before they reached 15 years of age $(n=18301)$. Last, we removed individuals with missing data on parental labour market exposures $(n=7603)$. Our final sample 
consisted of $88.6 \%$ of the targeted population $(n=526167)$. The sample included 262267 cousins and 216424 siblings nested within 114671 extended and 105470 nuclear families.

\section{Measures: exposure variables}

\section{Childhood family income throughout ages 1 to 15 years}

We calculated mean disposable family income (net sum of wage earnings, welfare and retirement benefits, etc.) of both biological parents for each offspring and year between 1990 and 2008 . Income measures were inflation-adjusted to 1990 values according to the consumer price index provided by Statistics Sweden (http:// www.scb.se/en_/). Econometric researchers have long recognised that single annual income exposure measures generally suffer from substantial measurement error because of their inability to accurately depict long-term SES, often leading to attenuation bias. ${ }^{18,19}$ Therefore, annual variables were used to calculate the mean parental income throughout each offspring's childhood (ages 1 through 15).

Early critics challenged the linearity assumption used by studies adopting continuous income measures by contending that criminality is largely confined to the lowest social strata, often referred to as 'the underclass' or 'the poor', with little to no difference being found between the strata in the mid to upper ranges of the income distribution. ${ }^{20}$ Others have argued that the cause of the spurious correlations are because of separate mechanisms promoting deviant behaviours on both ends of the income distribution resulting in weak mean predictions. ${ }^{1}$ We decided, therefore, to test potential non-linear effects by categorising our income measure in quintiles.

\section{Confounders}

Gender, birth year and birth order (dichotomous; first born and other) were included in all models. We also adjusted for highest parental education (divided into primary, secondary and tertiary level qualifications) and parental ages (five age categories; $<20$, $20-25,25-30,30-35$ and $>35$ ) at the time of the first-born child and parental history of ever being admitted to hospital for a mental disorder (ICD-8/9: 290-315; ICD-10: F00-F99).

\section{Measures: outcome variables}

Violent crime was defined as a conviction for homicide, assault, robbery, threats and violence against an officer, gross violation of a person's/woman's integrity, unlawful threats, unlawful coercion, kidnapping, illegal confinement, arson, intimidation, or sexual offences (rape, indecent assault, indecent exposure or child molestation, but excluding prostitution, hiring of prostitutes or possession of child pornography). ${ }^{21}$

In line with previous studies using Swedish total population data, ${ }^{8,22}$ we used an omnibus measure of substance misuse consisting of convictions of any drug-related crimes (defined as crimes against the Narcotic Drugs Act (SFS 1968:64) or driving under the influence of alcohol and/or illicit substances) or having been diagnosed with an alcohol- or drug-misuse-related disease in in-patient or out-patient settings (ICD-8: 291, 303-4, 571, E853, E856.4, E859, E860, N980; ICD-9: 291, 303-5, 357.5, 425.5, 535.3, 571.0-571.3, E850, E854.1-2, E855.2, E860, N980; ICD-10: F10, G32.2, G62.1, G72.1, I42.6, K29.2, K70, K85, X41-2, X45, X61-2, X65, Y11 (with T43.6), Y12 (with T40) and Y15 (with T51)).

\section{Statistical analyses}

To account for time at risk, we calculated hazard ratios (HRs) with corresponding 95\% confidence intervals for adolescent violent crime or substance misuse by fitting Cox proportional hazards regression models to the data. The participants entered the study at their fifteenth birthday and were subsequently followed up for a median time of 3.5 years. The maximum follow-up time was 6 years. Those who emigrated or died during follow-up were censored.

We fitted two separate models for the entire sample ( $n=526167)$ that gradually adjusted for observed confounding variables. Model I adjusted for gender, birth year and birth order, whereas Model II also adjusted for highest parental education, parental ages at the time of the first-born child and parental history of admission to hospital for a mental disorder.

To assess the effects also of unobserved genetic and environmental factors, we fitted stratified Cox regression models to cousin $(n=262267)$ and sibling $(n=216424)$ samples with extended or nuclear family as stratum, respectively. The stratified models allow for the estimation of heterogeneous baseline hazard rates across families and thus capture unobserved familial factors. ${ }^{23}$ This also implies that exposure comparisons are made within families. ${ }^{24}$ Model III was fitted to the cousin sample and adjusted for observed confounders and unobserved within extended-family factors. Model IV was fitted on the sibling sample and accounted for unobserved nuclear family factors and for gender, birth year and birth order.

Cousin and sibling correlations on the exposure variable were calculated based on a varying-intercepts, mixed-effects model where the intercepts are allowed to vary across families. ${ }^{25}$ The magnitude of the variation was expressed as an intraclass correlation (ICC). ${ }^{26}$ The ICC measures the degree to which observations are similar to one another within clusters; in this case cousins and siblings nested within extended and nuclear family clusters. The measure ranges between 0 and 1 , where the latter implies that cousins and siblings have identical exposure values within families.

All models were fitted in Stata 12.1 IC for Mac.

\section{Results}

Demographic sample characteristics are presented in Table 1. Adolescent violent crime and substance misuse rates were inversely correlated with the childhood family income. As an example, children of parents in the lowest income quintile experienced a rate of 11.05 per 1000 person-years of being convicted of a violent crime while the same estimate was 1.77 for the children of parents in the highest income quintile.

Table 2 presents results from multivariable Cox regression models; children of parents in the lowest income quintile had an almost seven-fold increased hazard of being convicted of violent crime (crude $\mathrm{HR}=6.78,95 \% \mathrm{CI} 6.23-7.38$ ) and a two-fold increase of substance misuse ( $\mathrm{HR}=2.45,95 \% \mathrm{CI}: 2.32-2.58)$ in adolescence compared with peers whose parents were in the fifth quintile (Model I).

When we made adjustments for observed family-wide risk factors (Model II), the effects of childhood family income on violent criminal convictions were significantly attenuated but remained strong $(\mathrm{HR}=3.93,95 \% \mathrm{CI} 3.59-4.30)$. Controlling for family-wide risk factors also affected the association with substance misuse ( $\mathrm{HR}=1.98,95 \%$ CI 1.86-2.10). Model III expanded on Model II by also accounting for unobserved familial risk factors within extended families through cousin comparisons. This adjustment reduced the hazard ratios by $50 \%$ and $25 \%$ for adolescent violent crime and substance misuse, respectively. Finally, we studied the effects of unobserved familial risk factors within nuclear families using sibling comparisons (Model IV). 
Table 1 Demographic characteristics for all children born in Sweden 1989-1993 that were included in a study of childhood family income (ages 1-15 years) and violent crime convictions and substance misuse during adolescence (ages 15-21 years)

\begin{tabular}{|c|c|c|c|c|}
\hline \multirow[b]{2}{*}{ Variable } & \multirow[b]{2}{*}{$n$} & \multirow[b]{2}{*}{$\%$} & \multicolumn{2}{|c|}{ Rate per 1000 person-years } \\
\hline & & & Adolescent violent crime & Adolescent substance misuse \\
\hline Total sample & 526167 & 100.00 & 5.12 & 7.36 \\
\hline \multicolumn{5}{|l|}{ Gender } \\
\hline Male & 269625 & 51.24 & 8.20 & 8.28 \\
\hline Female & 256542 & 48.76 & 1.91 & 6.40 \\
\hline \multicolumn{5}{|l|}{ Birth year } \\
\hline 1989 & 102687 & 19.52 & 4.31 & 6.93 \\
\hline 1990 & 108641 & 20.65 & 5.21 & 7.87 \\
\hline 1991 & 108897 & 20.70 & 5.39 & 7.51 \\
\hline 1992 & 106435 & 20.23 & 6.00 & 7.47 \\
\hline 1993 & 99507 & 18.91 & 5.60 & 6.79 \\
\hline \multicolumn{5}{|l|}{ Birth order } \\
\hline First born & 215598 & 40.98 & 4.48 & 6.73 \\
\hline Other & 310569 & 59.02 & 5.56 & 7.81 \\
\hline \multicolumn{5}{|c|}{ Mean parental disposable income } \\
\hline Quintile 1 (lowest) & 105234 & 20.00 & 11.05 & 12.45 \\
\hline Quintile 2 & 105233 & 20.00 & 6.04 & 8.03 \\
\hline Quintile 3 & 105234 & 20.00 & 3.60 & 5.60 \\
\hline Quintile 4 & 105233 & 20.00 & 2.86 & 5.25 \\
\hline Quintile 5 (highest) & 105233 & 20.00 & 1.77 & 5.30 \\
\hline
\end{tabular}

\begin{tabular}{|c|c|c|c|c|c|c|c|c|}
\hline & \multicolumn{4}{|c|}{ Adolescent violent crime, hazard ratio $(95 \% \mathrm{Cl})$} & \multicolumn{4}{|c|}{ Adolescent substance misuse, hazard ratio $(95 \% \mathrm{Cl})$} \\
\hline & Model I & Model II & Model III & Model IV & Model I & Model II & Model III & Model IV \\
\hline Quintile 1 (low) & $6.78(6.23-7.38)$ & $3.93(3.59-4.30)$ & $1.89(1.40-2.56)$ & $0.95(0.44-2.03)$ & $2.45(2.32-2.58)$ & $1.98(1.86-2.10)$ & $1.53(1.24-1.90)$ & $1.11(0.62-1.98)$ \\
\hline Quintile 2 & $3.66(3.35-4.00)$ & $2.50(2.28-2.74)$ & $1.46(1.09-1.95)$ & $0.81(0.41-1.61)$ & $1.56(1.47-1.66)$ & $1.39(1.31-1.48)$ & $1.19(0.97-1.45)$ & $1.31(0.81-2.13)$ \\
\hline Quintile 3 & $2.14(1.95-2.36)$ & $1.61(1.46-1.77)$ & $1.04(0.78-1.40)$ & $0.76(0.42-1.39)$ & $1.08(1.02-1.15)$ & $1.02(0.95-1.08)$ & $0.96(0.79-1.18)$ & $1.12(0.76-1.67)$ \\
\hline Quintile 4 & $1.64(1.48-1.81)$ & $1.34(1.21-1.48)$ & $0.80(0.60-1.06)$ & $0.64(0.39-1.05)$ & $1.00(0.93-1.06)$ & $0.96(0.90-1.03)$ & $0.98(0.81-1.17)$ & $1.09(0.81-1.47)$ \\
\hline Quintile 5 (high) & Reference & Reference & Reference & Reference & Reference & Reference & Reference & Reference \\
\hline
\end{tabular}

The associations between childhood family income and the outcomes disappeared completely; hazard ratios were $0.95(95 \%$ CI 0.44-2.03) for violent crime and 1.11 (95\% CI 0.62-1.98) for substance misuse, respectively. This suggested that unobserved familial factors fully accounted for the increased hazard ratios found in previous models.

\section{Sensitivity analyses}

Sibling correlations for childhood family income were, expectedly, rather high (Table 3 ), suggesting that the within-family variability was somewhat limited. Consequently, we re-fitted models presented in Table 2 to the childhood family income exposure variables covering single-year age periods (online Table DS1). Sibling correlations for the latter were 0.57-0.74. Despite larger heterogeneity between siblings in these exposures, the results remained quite similar.

As suggested in Table 4, we could not find any period effects of the timing of exposures on substance misuse. The crude associations presented in Model I were high, but consistently appeared explained by familial factors (Model IV). Differences between estimates for male-only and total population samples were small. By contrast, the female-only estimates indicated low precision with wide confidence intervals, especially for violent convictions within families. The discrepancies across estimates for the different birth order subsamples and analyses excluding second-generation immigrants from non-Nordic countries and the total population sample were marginal.

The extent to which other non-linear categorisations (i.e. tertiles and deciles) of childhood family income had an impact on the results was tested and we found negligible differences (data not presented; available from the authors on request).

In addition, we explored whether results were explained by relatively low rates of our outcome variables by re-fitting models to the following alternative outcomes: (a) any criminal conviction and (b) any property conviction. Corresponding rates were 25.27 and 10.70 per 1000 person-years, respectively. The general pattern of effects found in the main analyses remained (online Table DS2), and the magnitudes of estimates were also very similar to those of models predicting substance misuse (seen in Tables 2 and 4).

Table 3 Cousin and sibling intraclass correlations (ICCS) of childhood family income exposure by age periods

\begin{tabular}{|lcc|}
\multirow{2}{*}{ of childhood family income exposure by age periods } \\
\cline { 2 - 3 } Childhood family income & \multicolumn{2}{c|}{ ICC $(95 \% \mathrm{Cl})$} \\
\hline Ages $1-5$ years & $0.62(0.62-0.63)$ & $0.90(0.90-0.90)$ \\
\hline Ages 6-10 years & $0.65(0.65-0.65)$ & $0.90(0.90-0.90)$ \\
\hline Ages 11-15 years & $0.65(0.64-0.65)$ & $0.91(0.91-0.91)$ \\
\hline Ages 1-15 years & $0.69(0.69-0.70)$ & $0.96(0.96-0.96)$ \\
\hline
\end{tabular}


Table 4 Sensitivity analyses: relative risks as a function of childhood family income stratified by exposure age periods, gender, number of children in household, birth order and parental immigrant status ${ }^{\mathrm{a}}$

\begin{tabular}{|c|c|c|c|c|}
\hline & \multicolumn{2}{|c|}{ Adolescent violent crime, hazard ratio $(95 \% \mathrm{Cl})$} & \multicolumn{2}{|c|}{ Adolescent substance misuse, hazard ratio $(95 \% \mathrm{Cl})$} \\
\hline & Model I & Model IV & Model I & Model IV \\
\hline Ages $1-15$ years (reference) & $6.78(6.23-7.38)$ & $0.95(0.44-2.03)$ & $2.45(2.32-2.58)$ & $1.11(0.62-1.98)$ \\
\hline Ages $1-5$ years & $4.36(4.06-4.68)$ & $0.76(0.46-1.24)$ & $2.10(2.00-2.22)$ & $0.98(0.65-1.48)$ \\
\hline Ages $6-10$ years & $5.93(5.46-6.45)$ & $0.91(0.54-1.55)$ & $2.32(2.20-2.45)$ & $1.17(0.77-1.79)$ \\
\hline Ages $11-15$ years & $6.06(5.57-6.59)$ & $0.59(0.34-1.03)$ & $2.28(2.16-2.40)$ & $1.03(0.67-1.59)$ \\
\hline Males only, ages $1-15$ years & $6.39(5.82-7.01)$ & $0.51(0.24-1.12)$ & $2.42(2.25-2.60)$ & $0.84(0.37-1.92)$ \\
\hline Females only, ages $1-15$ years & $8.95(7.24-11.08)$ & $1.32(0.24-7.19)$ & $2.48(2.28-2.70)$ & $1.15(0.46-2.86)$ \\
\hline $\begin{array}{l}\text { Single children households only, } \\
\text { ages 1-15 years }\end{array}$ & $5.87(3.70-9.29)$ & N/A & $2.45(1.89-3.17)$ & N/A \\
\hline First-born only, ages $1-15$ years & $7.26(6.19-8.53)$ & N/A & $2.57(2.34-2.83)$ & N/A \\
\hline Other birth order, ages $1-15$ years & $6.45(5.83-7.13)$ & $1.44(0.49-4.22)$ & $2.35(2.20-2.52)$ & $0.82(0.32-2.06)$ \\
\hline $\begin{array}{l}\text { Nordic-born parents only, } \\
\text { ages } 1-15 \text { years }\end{array}$ & $6.72(6.17-7.32)$ & $0.98(0.45-2.11)$ & $2.45(2.32-2.59)$ & $1.11(0.62-1.99)$ \\
\hline
\end{tabular}

Finally, we investigated whether the results were specific to the childhood SES exposure variable by re-fitting the models to an alternative indicator; parental welfare recipiency between ages 1 through 15. Individuals who receive means-tested welfare benefits in Sweden are not primarily characterised by their lack of financial means; they are a selected group with a wide range of psychosocial issues. ${ }^{27}$ The results nonetheless matched those exploring childhood family income (online Table DS3).

\section{Discussion}

Using traditional epidemiological methods, we found that low income in one's family of origin was indeed associated with higher risk of violent offending and substance misuse during adolescence. However, the excess risks became marginal or disappeared completely when we gradually adjusted for familial risk factors of these associations by studying within-extended family and within nuclear-family estimates (with cousin and sibling controls, respectively). This held true when childhood SES was defined either as parental disposable income or welfare recipiency throughout child ages 1-15 years. Sensitivity analyses proved the results were robust across gender, ethnicity and age periods and were not influenced by limited within-family variability in the exposure variables.

Our finding that the associations between childhood family income and adolescent violent criminality and substance misuse are unlikely to be causal has been suggested in prior systematic reviews on SES and criminality. ${ }^{28-31}$ On the other hand, smaller, US-based, quasi-experimental studies on behavioural problems have indicated causal effects. ${ }^{10-12}$ The diverging results may have at least two plausible explanations. First, outcome variables are not always directly comparable between studies; whereas we have focused on severe criminal offending and substance misuse, earlier studies addressed less severe antisocial behaviours and conduct problems. Second, it could be that Sweden's comprehensive welfare state actually mitigates the possible adverse effects of growing up with limited material resources. ${ }^{32}$

Our results indicate therefore that prevention efforts that specifically aim to decrease rates of violent offending and substance misuse should target a wider range of familial risk factors than merely parental income. This recommendation is in line with contemporary research that defines early socioeconomic exposures as distal risk factors because of their lack of direct associations with delinquency and antisocial behaviours, whereas familial risk factors (such as the quality of the parent-child relationship, family dissolution and parental criminality) are instead viewed as proximal risk factors because they tend to explain the majority of the variance in such outcomes. ${ }^{33,34}$ Further large-scale, genetically informative, quasi-experimental studies are thus going to be crucial in identifying and determining potentially causal familial predictors of violent criminality and substance misuse.

\section{Strengths and weaknesses}

In the largest study of childhood SES, adolescent violent crime and substance misuse to date (with a total population study of five birth cohorts of children born 1989-1993), we addressed and ruled out possible effects from various methodological weaknesses pointed out previously. ${ }^{1,18-20,35}$ Measurement error was minimised by the use of well-defined, prospectively and objectively gathered family income measures spanning 15 years. ${ }^{19}$ The extensive 15-year exposure period made it possible to study potential temporal variability in effects, including both the timing and persistence of low childhood SES.

Three methodological considerations are important when interpreting the present findings. First, we cannot exclude potential bias from cohort effects that might have affected the associations between childhood family SES and outcome, because the included cohorts were infants or preschool children when Sweden underwent a major economic recession in the mid-1990s with quadrupling unemployment rates and substantially rationalised welfare programmes. ${ }^{36}$ We were unable to explore such bias because we did not have access to yearly parental income data prior to 1990. However, if anything, cohort effects bias may have led to an overestimation of unadjusted effects seen before accounting for unobserved familial risk factors.

Second, our approach of using nationwide registry data confined our analyses to arguably more severe cases that had been registered by the legal and clinical services for their actions. It is obviously an empirical question whether the results for non-diagnosed cases would be similar.

Third, the sibling-comparison design makes several important assumptions and requires a large sample size. ${ }^{9,37,38}$ In principle, only sibling pairs discordant on both exposure and outcome contribute to the analyses. We identified 116875 siblings in 56551 families who were discordant for childhood family income (measured in deciles). Among these discordant siblings, 3195 were 
further discordant for violent criminal convictions and 5507 for substance misuse. Although they might seem small, these sample sizes are still larger than in most of the previous studies. Moreover, the sibling- comparison design assumes that the results of discordant siblings are generalisable to the total population. We found no income differences when comparing the discordant siblings to the total population; $t(526165)=1.25, P=0.21$. Thus, our findings do not seem to follow from poor statistical power, neither does it seem that results from discordant siblings are not generalisable.

\section{Implications}

The present study highlights the importance of adjusting for unobserved familial risk factors when studying the impact of childhood SES on later adverse outcomes, such as violent crime and substance misuse; hence, claims of causal effects after only adjusting for observed covariates should be viewed with caution. We found strong inverse correlations that were explained fully by unobserved familial risk factors shared by children growing up in low SES households. Future research is needed to validate these results in other contexts and elucidate the nature of the mechanisms, including the relative contributions of genes and environments.

\footnotetext{
Amir Sariaslan, MSc, Henrik Larsson, PhD, Department of Medical Epidemiology and Biostatistics, Karolinska Institutet, Stockholm, Sweden; Brian D'Onofrio, PhD, Department of Psychological and Brain Sciences, Indiana University, Bloomington, Indiana, USA; Niklas Långström, MD, PhD, Paul Lichtenstein, PhD, Department of Medical Epidemiology and Biostatistics, Karolinska Institutet, Stockholm, Sweden

Correspondence: Amir Sariaslan, Karolinska Institutet, Department of Medical Epidemiology and Biostatistics, PO Box 281, SE-171 77 Stockholm, Sweden. Email: Amir.Sariaslan@ki.se

First received 26 Jul 2013, final revision 10 Mar 2014, accepted 10 Jun 2014
}

\section{Funding}

The study was supported by the Swedish Council for Working Life and Social Research, the Swedish Research Council (2010-3184; 2011-2492) and the National Institute of Child Health
and Human Development (HD061817). The funders had no role in the design and conduct of the study; collection, management, analysis, and interpretation of the data; and preparation, review, or approval of the manuscript.

\section{References}

1 Wright BRE, Caspi A, Moffitt TE, Miech RA, Silva PA. Reconsidering the relationship between SES and delinquency: causation but not correlation. Criminology 1999; 37: 175-94.

2 Williams FP, McShane MD. Criminological Theory: Selected Classic Readings. Anderson Publishing, 1998.

3 Galloway TA, Skardhamar T. Does parental income matter for onset of offending? Eur J Criminology 2010; 7: 424-41.

4 Sareen J, Afifi TO, McMillan KA, Asmundson GJ. Relationship between household income and mental disorders: findings from a population-based longitudinal study. Arch Gen Psychiatry 2011; 68: 419.

5 McMillan KA, Enns MW, Asmundson GJ, Sareen J. The association between income and distress, mental disorders, and suicidal ideation and attempts: findings from the Collaborative Psychiatric Epidemiology Surveys. J Clin Psychiatry 2010; 71: 1168-75.

6 Sariaslan A, Långström N, D'Onofrio B, Hallqvist J, Franck J, Lichtenstein P. The impact of neighbourhood deprivation on adolescent violent criminality and substance misuse: a longitudinal, quasi-experimental study of the total Swedish population. Int J Epidemiol 2013; 42: 1057-66.

7 Frisell $T$, Lichtenstein $P$, Långström N. Violent crime runs in families: a total population study of 12.5 million individuals. Psychol Med 2011; 41: 97-105.

8 Kendler KS, Sundquist K, Ohlsson H, Palmér K, Maes H, Winkleby MA, et al. Genetic and familial environmental influences on the risk for drug abuse: a national Swedish adoption study. Arch Gen Psychiatry 2012; 69: 690-7.

9 D'Onofrio BM, Lahey BB, Turkheimer E, Lichtenstein P. Critical need for family-based, quasi-experimental designs in integrating genetic and social science research. Am J Public Health 2013; 103: S46-55.
10 D'Onofrio BM, Goodnight JA, Van Hulle CA, Rodgers JL, Rathouz PJ, Waldman ID, et al. A quasi-experimental analysis of the association between family income and offspring conduct problems. J Abnorm Child Psychol 2009; 37: $415-29$

11 Hao L, Matsueda RL. Family dynamics through childhood: a sibling model of behavior problems. Soc Sci Res 2006; 35: 500-24.

12 Blau DM. The effect of income on child development. Rev Econ Stat 1999; 81: $261-76$.

13 Jaffee SR, Strait LB, Odgers CL. From correlates to causes: can quasiexperimental studies and statistical innovations bring us closer to identifying the causes of antisocial behavior? Psychol Bull 2012; 138: 272-95.

14 Cnattingius S, Ericson A, Gunnarskog J, Källén B. A quality study of a medical birth registry. Scand J Public Healht 1990; 18: 143-8.

15 World Health Organization. International Statistical Classification of Diseases and Related Health Problems (ICD-8). WHO, 1967.

16 World Health Organization. International Statistical Classification of Diseases and Related Health Problems (ICD-9). WHO, 1978.

17 World Health Organization. The ICD-10 Classification of Mental and Behavioural Disorders: Clinical Descriptions and Diagnostic Guidelines. WHO, 1992.

18 Solon G. Intergenerational income mobility in the United States. Am Econ Rev 1992; 82: 393-408.

19 Bjerk D. Measuring the relationship between youth criminal participation and household economic resources. J Quant Criminol 2007; 23): 23-39.

20 Dunaway RG, Cullen FT, Burton VS, Evans TD. The myth of social class and crime revisited: an examination of class and adult criminality. Criminology 2000; 38: 589-632.

21 Fazel S, Grann M. The population impact of severe mental illness on violent crime. Am J Psychiatry 2006; 163: 1397-403.

22 D'Onofrio BM, Rickert ME, Långström N, Donahue KL, Coyne CA, Larsson H, et al. Familial confounding of the association between maternal smoking during pregnancy and offspring substance use and problems: converging evidence across samples and measures. Arch Gen Psychiatry 2012; 69: 1140.

23 Liu X. Survival Analysis: Models and Applications. John Wiley \& Sons, 2012.

24 Carlin JB, Gurrin LC, Sterne JA, Morley R, Dwyer T. Regression models for twin studies: a critical review. Int J Epidemiol 2005; 34: 1089-99.

25 Gelman A, Hill J. Data Analysis using Regression and Multilevel/Hierarchical Models. Cambridge University Press, 2006.

26 Merlo J. Multilevel analytical approaches in social epidemiology: measures of health variation compared with traditional measures of association. J Epidemiol Community Health 2003; 57: 550-2.

27 Stenberg SÅ. Inheritance of welfare recipiency: an intergenerational study of social assistance recipiency in postwar Sweden. J Marriage Fam 2000; 62: 228-39.

28 Tittle CR, Villemez WJ, Smith DA. The myth of social class and criminality: an empirical assessment of the empirical evidence. Am Sociol Rev 1978; 43: 643-56.

29 Tittle CR. Social class and criminal behavior: a critique of the theoretical foundation. Soc Forces 1983; 62: 334-58.

30 Ellis L, McDonald JN. Crime, delinquency, and social status: a reconsideration. J Offender Rehabil 2000; 32: 23-52.

31 Daniel JZ, Hickman M, Macleod J, Wiles N, Lingford-Hughes A, Farrell M, et al. Is socioeconomic status in early life associated with drug use? A systematic review of the evidence. Drug Alcohol Rev 2009; 28: 142-53.

32 Aaltonen M, Kivivuori J, Martikainen P. Social determinants of crime in a welfare state: do they still matter? Acta Sociol 2011; 54: 161-81.

33 Sampson RJ, Laub JH. Crime in The Making: Pathways and Turning Points Through Life. Harvard University Press, 1995.

34 Wikström P-OW, Oberwittler D, Treiber K, Hardie K. Breaking Rules: The Social and Situational Dynamics of Young People's Urban Crime. Oxford University Press, 2012.

35 Jarjoura GR, Triplett RA, Brinker GP. Growing up poor: examining the link between persistent childhood poverty and delinquency. I Quant Criminol 2002; 18: 159-87.

36 Bergmark $\AA$, Palme J. Welfare and the unemployment crisis: Sweden in the 1990s. Int J Soc Welf 2003; 12: 108-22.

37 Lahey BB, D'Onofrio BM. All in the family: comparing siblings to test causal hypotheses regarding environmental influences on behavior. Curr Direc Psychol Sci 2010; 19: 319-23.

38 Frisell T, Öberg S, Kuja-Halkola R, Sjölander A. Sibling comparison designs: bias from non-shared confounders and measurement error. Epidemiology 2012; 23: 713-20. 